World Bank Reprint Series: Number 112

Mohan Munasinghe and Mark Gellerson

\title{
Economic Criteria for Optimizing Power System Reliability Levels
}

Reprinted with permission from The Bel' Journal of Economics, vol. 10, no. 1 (Spring 1979), pp. 353-65 


\title{
Economic criteria for optimizing power system reliability levels
}

\author{
Mohan Munasinghe \\ Central Projects Staff \\ World Bank \\ and \\ Mark Gellerson \\ Department of Economics \\ Southern Illinois University
}

The standards of reliability of electris:y supply have previonsly been dotermine'd on a rule-of-thumb basis. This paper presents a generalized simulation model for optimizing the reliability level by compuring the social benefits and costs of changes in power system reliability. The supply side costs of increasing system reliability can be determined from straightforward enginecring considerations. On the demand side, the benefits to electricity us'ris consist of cost savings from averted power failures or anage's which may be measured by the disruption of the output streams owing to idle input factors and spoilage. The theory is applied to the case study of Cascar'el, Brazil to determine a range of optimum reliability levels for long-range electric pow'r distribution system planning. The principal outage costs are incurred by industrial and residential consumers.

\section{Introduction}

- Reliability standards for electricity supply in most countries are based on past engineering practice and rules-of-thumb. Thus there is a need to develop a more rigorous economic framework which can be used to optimize electric power system reliability. The issue of optimal levels of capacity and electric power reliability has rect: $r$ ed attention recently as part of the more general economic literature conr stning public utility pricing under conditions of uncertainty (stochastic demand and supply) (Brown and Johnson, 1969; Crew and

The authors are grateful to Walter Scott and the staff of Compania Paranaense de Fnergia Eletrica for their assistance in carrying out the engineering aspects of the case study, and to the Editorial Board and an anonymous referee for detailed comments on an earlier draft of this paper. The co.itributions of Monica Scott and $: \therefore$ id Teitelbaum in computer programming are also acknowledged. This work was carried out as a part of World Bank research study No. RES 670-67. The views expressed are those of the authors and not necessarily those of the World Bank. 
Kleindorfer, 1976, 1978; Sherman and Visscher, 1978). In this case the utility is typically modeled as a net welfare maximizer, where net social welfare equals the difference between expected willingness-to-pay for electricity and either expected supply costs (Brown and Johnson, 1969) or the sum of expected supily costs plus the costs of rationing electricity according to consumers' willingnessto-pay (Crew and Kleindorfer, 1976, 1978). Such studies indicate that, idcally, both price and reliability should be jointly optimized to achieve maximum net social welfare. We may summarize this complex analysis in a very simplified form as follows: economic efficiency would be maximized if price was set equal to marginal cost, and the capacity level was fixed (thus also determining the reliability level) at the point where the marginal cost of adding to capicity (net of the energy saved) was equal to the marginal consumer benefits realized by the corresponding electric power shortages which were averted.

The short-run marginal cost (SRMC) may be defined as the cost of meeting additional electricity consumption, with capacity fixed. Therefore, in a given period. SRMC would be equal to the marginal energy costs plus shortage costs from unmet demand; during the off-peak hours, since shortages are highly unlikely to definition, shortage costs could be neglected. The long-run marginal cost (LRMC) is the cost of meeting an increase in consumption (sustained indefinitely into the future), in a situation where capacity adjustments are possible. Thus LRMC would include both marginal energy and catpacity costs. When the capacity (and therefore the reliability level) is optimal, SRMC and LRMC cuincide.

The method of determining optimal reliability described in this paper differs from the earlier approaches. First, in the previous studies, electricity is treated as a good which directly provides consumers with satisfaction. Therefore. shortage costs are measured primarily in terms of the resulting reduction in consumer surplus (plus rationing costs in the case of Crew and Kleindorfer (1970, 1978)). However, in our paper, clectricity is viewed as being an intermediate product, which is used to produce final goods that are demanded by consumers. Thus we measuric uutage ${ }^{1}$ costs in terms of the effects on the production of final goods and services in various sectors of the economy." By taking this approach, the problem of having to use consumers' willingness-to-pay for planned electricity consumption as a measure of the costs resulting from unexpected outages, is avoided. The consumer's surplus approach is questionable. since outages may distupt other activitics complementary to electricity consumption. Thus actual short-term outage costs may greatly exceed those estimated on the basis of willingnesis-to-pay for planned consumption (Turvey and Anderson, 1977, Chapter 14). Moreover, the method of estimating outage costs described below does not necessarily assume that when outages occur load shedding takes place accorciing to willingness-to-pay.

Second, given a rationing or load-shedding scheme, previous studies maximized net welfare by satisfying joint first-order conditions with respect to juices and capacity, indicating that partial approaches which attempt to "optimize" reliability in the presence of given prices cannot ensure that resulting net benefits are maximized. However, in practice, electricity tariffs are often not readily.

${ }^{1}$ The term outage is used to represent all ispects of electric power shortitices includmy supply interruplions. voltage and frequency changen. However, in the case study only the offects of intermuption are considered.

If the market prices of inputs and outputs are distorted, appropriate shadow prices have to be used. For details, see M. Munising/ke and J.J. Warford (1978). 
subject to change. Therefore, this study develops a method of optimizing reliability by weighing the costs and benefits associated with alternative levels of reliability, subject to initially fixed prices. To the extent that this is accomplished, then the net benefits of electricity consumption should at least be increased. Once the optimal reliability level is determined on the first round, tariffs can be revised to reflect any changes in the cost of supr'ying electricity implied by the new reliability level. With this new level of tariffs and the resulting revised demand forecast, reliability can be reoptimized; and the process can be continued until the self-consistent combination of tariffs and reliability that maximizes the net social benefits of supplying electricity is determined.

Appropriate methods of estimating outage costs for various catcgories of consumer are presented in Section 2 of this paper. Then in Section 3 wa develop a model which optimizes the reliability of electricity supply bu comparing the supply costs of meeting consumer demand for electricity at different levels of reliability with the corresponding outage costs. Finally, we apply the theory to the case study of Cascavel, Brazil, in Section 4, to determine a range of optimum reliability levels for an urban electric power distributic n system. Section 5 presents the conclusions.

\section{Estimation of outage costs}

Residential. The production of household outputs (Becker, 1965; Lanciaster, 1966) which utilize electricity as one of their principal inputs is particularly susceptible to outages. The most important of these outputs are housekeeping. nutrition, and leisure. At any given moment during the day, there is likely to be significant substitutability between electricity-using and nonelectricity-using housekeeping activities. Furthermore, over a given time period (e.g., 24 hours), housekeeping activities temporarily interrupted by an outage may be rescheduled without much difficulty. Therefore, outage costs associated with housekeeping may be considered small. In general, nutrition is an activity which could be severely hampered by outages occurring during periods of cooking. However, in the case of Cascavel no significant uutage cost was observed because cooking is done almost entirely by gas.

Leisure differs from the previously discussed houschold activities in ways which make the associated outage costs more significant. First, the enjoyment of leisure is constrained, at least for wage earners, to occur over a relatively fixed period of time. Second, the use of electricity could be considered essential to the enjoyment of certain leisure activities (e.g., TV watching, reading. etc.) during these night time hours; thus, there are very limited subulitution possibilities for nonelectricity-using activities during an outage which oceurs in this period, at least in the short run. A model of household activity based on the consumer's labor-leisure choice, and presented elsewhere (Munasinghe, 1977), yields an expression for outage cost which embodies the opportunity couts of other complementary inputs used to produce electricity-dependent leisure, which are made idle by the lack of clectricity. Therefore, since the main opportunity cost involved is owing to the lost input of time, the houschold's net income earning rate provides an estimate of marginal outage cost during the leisure hours. ${ }^{3}$

\footnotetext{
It is assumed that housewives are not constrained to enjoy leisure only during the evening hours, and hence their outage costs are small. Therefore, it is porsible to avoid complications arising from having to estimate the value of housewives time (see, e.g. Gronau (1973)).
} 
The results of a survey of residential electricity consumers in Cascavel does confirm that: (a) the chief outage cost imposed on this category of user is the loss of leisure during a critical 1.5 hour period in the evening, and (b) the mean income earning rate for a household is an acceptable monetary measure of the marginal leisure loss due to an outage. ${ }^{4}$

Generally, the above measure of outage cost is considerably higher than the $v$. In terms of the (short-run) household demand curve for electricity, this underlines the fact that the $\mathrm{KW} W^{\prime} \mathrm{H}$ 's lost owing to a random outage are not always marginal. Therefore, the outage cost reflects not just the small wedge shaped area of consumers' surplus lying between the dow'nward sloping demand curve and the horizontal price line, owing to KWH's lost at the margin, but rather a much larger amount of consumers' surpius foregone corresponding to inframarginal KWH lost. ${ }^{5}$ Mo eover, even if the marginal $\mathrm{KWH}$ is lost, the resulting outage cost may be significantly greater than the above-described area of consumer surplus, because such an outage is unplanned, and thus leads to the forced idleness of complementary productive factors. The willingness of residential consumers to pay the equivalent of their net income earning rate to avoid evaning-time outages, is not surprising in terms of the absolute amounts of money involved, ${ }^{6}$ e.g., on this basis, in 1976 a typical electricity-using home in Cascavel with an annual income of $\mathrm{Cr} \$ 60,000$ (i.e., about ( $\$ 28.5$ per working hour), ${ }^{7}$ would have to pay only $\mathrm{Cr} \$ 57$ per annum more (i.e., about 6 percent of their annual electricity bill of $\mathrm{Cr} \$ 920)$, if the incidence of evening outages was halved from 4 to 2 hours per annum.

The principal advantage of this method for estimating the leisure costs of outages to residential consumers is its reliance on relatively easy-to-obtain income data. For example, as in the case of Cascavel, it is often possible to obtain a good relationship between family income and $\mathrm{KWH}$ electricity consumption for a typical sample. Therefore, on the basis of the electric utility company's billing records, the income levels of the electricity-using households may be estimated. However, the empirical test of the vilue of leisure lost as the result of an outage depends on the short-run willingness-to-pay criterion. ${ }^{8}$

A downward sloping demand curve for leisure would imply higher outage costs per unit time for outages of long duration (e.g., 2 hours), involving inframarginal units of leisure.

5 This point is often overlooked. See, for example, Webb (1977) and Priestman (1977).

${ }^{6}$ Note that this is a purely monetary measure. If there is dininishing inarginal utility of income/consumption, then it is possible to weight the outage costs, depending cn the average income level of the household. Such social weights, which should reflect socieises income distributional goals, would tend to reduce the disparits hetwen the dimlility of outages to low and high income households. See Squire and Van der Tak (1975).

7 U.S.\$1 = Cr\$12.5 (1976).

"However, there are several theoretical problems. furb, traditional wotk practices such as the 40-hour week, insufficient empliy ment upportunities, union rules concerning hours of work, and so on, may make it difficult to justify equating the wage to the marginal value of leisure. In the case of Cascavel, unemployment was very low as a result of rapid economic growih in the area, and union pressures were minimal; thus these problems m.1\} not be severe. Second, the cost to nonwage earning members of the family is effectively ignored by allowing only the wage eainers to represent the household as an income e.ırning unit. Third. there may be some outage expcctation, especially in areas where outages are frequent, wnich tend to reduce outage costs. In certain perverse cases, outages may even provide uulıt, e.g.. enjoyment of a novel hiluation. Finally, leisure may be enjoyed outside the home, in which case it should he treated separafel:. 
Industrial. Industrial consumers suffer outage costs because materials and products are spoiled, and normai production cannot take place. The cost of spoiled products and materials $(S P C)$ incurred by a given firm over one year can be measured as

$$
S P C=\sum_{i=1}^{f}\left[v\left(d_{i}\right)+m\left(d_{i}\right)\right] \frac{Q}{h},
$$

where $Q=$ total annual value-added, $H=$ hours of operation in a benchmark year, $f=$ frequency of outages per annum, $d=$ duration of the $i$ th outage, and $v\left(d_{i}\right)$ and $m\left(d_{i}\right)=$ value-added and the value of nonfactor inputs, respectively, embodied in the spoiled products and materials (with both $v\left(d_{i}\right)$ and $m\left(d_{i}\right)$ expressed as a fraction of average vaide-added per working hour).

Disrupted production results in an opportunity cost in the form of idle capital and labor $(I F C)$ which can be measured as

$$
I F C=\sum_{i=1}^{f}\left[\epsilon \cdot d_{i}+\bar{\epsilon} \cdot \gamma\left(d_{i}\right)\right] \cdot \frac{Q}{h},
$$

where $\epsilon$ and $\bar{\epsilon}$ are the fractions of normal output not produced during the outage and restart ${ }^{9}$ periods, respectively, and $\gamma\left(d_{i}\right)$ is the restart time for an outage of duration of $d_{i}$.

If slack productive capacity exists, then a fraction $\lambda$ of lost value-added ${ }^{\text {to }}$ can bo made up by using the productive capacity more intensively after the outage than during normal working hours. Therefore, à part of the outage costs $(R C)$ can be recovered: $R C=\lambda I F C$.

Firms which do not produce 24 hours per day also have the option of making up some fraction $\rho$ of lost output by working overtirne. In most cases it is unlikely that a profit-maximizing firm would have an economic incentive to do so. However, contractual obligations or other short-run constraints on a firm's behavior might lead to a decision to work overtime to make lost output. The hours of overtime production necessary to accomplish this are given by

$$
h_{0}=\rho \sum_{i=1}^{f}\left[v\left(d_{i}\right)+\left\{d_{i}+\gamma\left(d_{i}\right)\right\} \cdot(1-\lambda) \epsilon\right]
$$

and the opportunity cost of overtime production (OTC) can be measured as

$$
\text { OTC }=h_{0} \frac{(\bar{w})}{w} \frac{L}{h},
$$

where $L$ is annual labor value-added, $\bar{w}$ and $w$ are overtime and normal wage rates, respectively, ${ }^{11}$ and it is assumed that there is no opportunity cost of using cap tal during overtime production periods.

Thus, allowing for the possibility of both slack productive capacity and overtime production, a general measure of the costs of outages which affect a

\footnotetext{
9 Often production cannot begin immediately after the supply of electricity is restored, because there is a restart time during which machines must be cleaned, furnaces reheated, and so on; in most cases, $\epsilon=\bar{\epsilon}$, and therefore we adopt this simplifying assumption.

10 $\lambda$ varies with the time an outage occurs and its duration. However. an average value of $\lambda$ zan be calculated. In fact, in Cascavel $\lambda=0$ for most firms.

"In cases of wage distortion, shadow wage rates could be used to represent the opportunity cost of labor during both normal working hours and overtime.
} 
firm or industry over a given time period $(O C)$ can be determined:

$$
O C^{\prime}=\frac{Q}{h} \sum_{i=1}^{f}\left\{m\left(d_{i}\right)+\left[1-\rho\left(1 \cdot \frac{\bar{w}}{w} \cdot \frac{L}{Q}\right)\right]\left[v\left(d_{i}\right)+\left\{d_{i}+\gamma\left(d_{i}\right)\right\}(1-\lambda) \epsilon\right]\right\} .
$$

In most cases, $\lambda=0$ and $\rho=0$ so that

$$
O C^{I}=\frac{Q}{h} \sum_{i=1}^{f}\left[m\left(d_{i}\right)+v\left(d_{i}\right)+\left\{d_{i}+\gamma\left(d_{i}\right)\right\} \epsilon\right] .
$$

A survey of the 20 principal industrial users of electricity was conducted in Cascavel. On the basis of this survey, and using the methodology descrited above, we determined the costs of outages of various durations for each of the firms. These costs were weighted according to the firm's share of value-added in the industry and added, so as to give one set of observations relating outage costs and durations for each industry. Finally, the outage cost functions presented in Table 1 were estimated for each industry.

Other. The provision of public illumination is constrained to occur during the hours of darkness, and the service cannot be supplied without electricity. Thus an outage which affects public illumination imposes a cost in the form of reduced community' well-being since some of the benefits of public illumination, e.g., security and improved motoring safety, are foregone. One can arguc that these foregone benefits are worth at least as much as the net supply cost which the community would have incurred for public illumination during the

TABLE 1

\begin{tabular}{|c|c|c|c|c|c|}
\hline \multirow[b]{2}{*}{ No. } & \multirow[b]{2}{*}{ INDUSTRY } & \multirow{2}{*}{$\begin{array}{l}\text { OC FUNCTION } \\
\text { TYPE }\end{array}$} & \multicolumn{2}{|c|}{ ESTIMATED COEFFICIENTS ${ }^{1}$} & \multirow{2}{*}{ REMARKS 3} \\
\hline & & & $\begin{array}{c}a \\
\left(\times 10^{-4}\right)\end{array}$ & $\begin{array}{c}b \\
\left(\times 10^{-4}\right)\end{array}$ & \\
\hline $\begin{array}{l}\text { A.1, } \\
\& \text { B. } 3\end{array}$ & $\begin{array}{l}\text { MECHANICAL AND } \\
\text { METALLURGY }\end{array}$ & LINEAR & 0.0013 & 3.9 & D \\
\hline A. 2 & $\begin{array}{l}\text { NONMETALLIC } \\
\text { MINFRALS }\end{array}$ & LINEAR & 0.077 & 3.5 & D \\
\hline A.3 & WOOD & LINEAR & 0.094 & 3.9 & $b$ \\
\hline A.4 & VEGETABLE OILS & $\begin{array}{l}\text { PIECEWISE - } \\
\text { LINEAR }\end{array}$ & $\begin{array}{l}0.037 \\
3.6 \\
\end{array}$ & $\begin{array}{l}2.1 \\
1.9 \\
\end{array}$ & $\begin{array}{l}d<0.5 \text { HOURS, A } \\
d \geq 0.5 \text { HOURS, A }\end{array}$ \\
\hline \multirow{2}{*}{ A.5 } & \multirow{2}{*}{ FOOD AND BEVERAGES } & $\begin{array}{l}\text { PIECEW!SE- } \\
\text { LINEAR }\end{array}$ & $\begin{array}{l}1.22 \\
7.07\end{array}$ & $\begin{array}{l}2.30 \\
2.02\end{array}$ & $\begin{array}{l}d<0.5 \text { HOURS, } D \\
d \geq 0.5 \text { HOURS, } D\end{array}$ \\
\hline & & LINEAR & 0.66 & 0.72 & $N$ \\
\hline A. 6 & OTHER & LOG & 7.2 & 2.9 & $d \geq 0.01$ HOURS, D \\
\hline B.2 & TELEPHONE & LINEAR & 0.002 & 1.1 & A \\
\hline B.3 & WATER TREATMENT & LINEAR & -0.27 & 1.1 & $\mathrm{~d} \geq 2$ HOURS, D \\
\hline \multicolumn{6}{|c|}{$\begin{array}{l}{ }^{2} \text { LINEAR AND LOG REFER TO FUNCTIONS OF THE TYPE C/Q }=(a+b . d) \text { AND } C / Q=\left(a+b . L_{0}=(10 d), \text { RESPEC }\right. \\
\text { TIVELY, WHERE } C=\text { OUTAGE COST, } Q=\text { ANNUAL VALUE ADDED, AND } d=\text { OUTAGE DURATION (HOURS). } \\
{ }^{3} D=\text { DAYTIME OPERATION, } N=\text { NIGHT-TIME OPERATION; } A=24 \text { HOUR OPERATION. }\end{array}$} \\
\hline
\end{tabular}

INDUSTRIAL OUTAGE COST FUNCTIONS 
outage periods. ${ }^{12}$ During a one-hour outage, such a minimum estimate of net cost would equal the annuitized value of capital equipment and routine maintenance expenditures per hour of use of the particular street lights affected by the outage; electricity costs are not included, since they are not incurred during outages.

Because of the lack of knowledge of the production process that goes on in hospitals, and the difficulty of measuring outputs, the measurement of outage costs for hospitals is more difficult and less exact than in the case of industrial firms discussed earlier. Two hospitals ( 80 beds and 200 beds) were surveyed to estimate the opportunity costs of both productive factors which are made idle (e.g., electricity-using equipment and labor) and intermediate products, such as blood and medicines, which might spoil because of outages. ${ }^{13}$ The principal outage costs were found to occur during the night period (i.e., 1900-0600 hours) as a result of idle labor and capital. The average cost was estimated to be Cr\$0.67 per hospital bed per hour of outage.

Outage costs for government offices and commercial customers were found to be minimal because work could often continue by daylight, and because there was usually sufficient slack during the normal hours of work for jobs delayed by any outage to be made up. Supermarkets and hotels reported minor amounts of spoilage for long outages, i.e., over five hours; however, such outages are extremely rare. The KWH consumption of rural consumers in the vicinity of Cascavel was less than one percent of the total in 1974, and their share of demand is unlikeiy to exceed 5 percent of the total even by 1996. Therefore, this category of consumer will not be considered in detail here.

\section{The optimization model}

Let the generalized measure $R$ characterize the reliability level of the electric power system over the time horizon being considered, and let $D$ be the corresponding demand for the service assuming a given price level. A simple expression for the net benefit of electricity consumption at given levels of reliability $R$, demand $D$, and assuming fixed tariffs may be written: $N B(R, D)=T B(D)$ - $O C(R, D)-S C(R, D)$, where $T B(D)$ is the total benefit from consumption at the level of demand $D$ if there were no outages, $O C(F, D)$ are the outage costs, ${ }^{14}$ and $S C(R, D)$ are the supply costs. Therefore, we have

$$
\frac{d(N B)}{d R}=-\frac{\partial}{\partial R}(O C+S C)+\frac{\partial D}{\partial R} \cdot \frac{\partial}{\partial D}(T B-O C-S C) .
$$

For purposes of the simulations carried out in this study, we assume that $\partial D / \partial R=0$ (i.e., for the range of reliability levels considered here, variations in $R$ will have negligible effects on predicted demand) and that variations in $R$

${ }^{12}$ It is unlikely that the decisions concerning marginal investments on public illumination would be made on the basis of explicit cust-henefil analyses. However, if street lighting is either much too inadequate, resulting in reduced security for citizens at night. or conversely far too extensive, leading to increased costs and municipal taxes, etc., then there will be public pressure on the city government to rectify the siluation.

${ }^{13}$ Estimating the costs resulting from possible losses of life is a task excceding the scope of this study; therefore, such costs are not considered here.

14 Note that $O C$ also depends on consumers expectations of reliability which are reluted to the actual reliability level. 
do not significantly affect consumers' expectations of reliability. Then the effects of an increase in reliability $|\Delta R|$ on net benefits may be written:

$$
\Delta N B=-\triangle O C-\triangle S C=|\triangle O C|-|\Delta S C|,
$$

where $\Delta O C=(\partial O C / \partial R) \Delta R$, and so on, and use has been made of the fact that $\partial O C / \partial R<0$ and $\partial S C / \partial R>0$. Therefore, to maximize the net economic benefits of supplying electricity to society, the reliability level should be increased as long as the corresponding decrease in outage costs exceeds the increase in supply costs, and vice versa.

We define the measure of reliability of electricity supply to any group of consumers in year $t$ as $^{15}$

$$
R_{t}=1-O E_{t} / T E_{t}
$$

and over a period of $T$ years, as

$$
R=1-\left[\sum_{t=0}^{r} \frac{O E_{t}}{(1+r)^{t}} / \sum_{t=0}^{T} \frac{T E_{t}}{(1+r)^{t}}\right],
$$

where $O E_{t}$ represents the electric energy not supplied because of outages in year $t$ and $T E_{t}$ represents the total electric energy that would have been supplied in year $t$ if there were no outages, and $r$ is the discount rate.

Consider Figure 1, which shows three possible evolutionary paths of system reliability for the given demand forecast starting from a relatively high level and extending over some planning time horizon; i.e., 0 to $T$. Path 2 represents the case in which expenditures on the power system are sufficient to maintain the medium level of reliability $R^{2}$. In paths 1 and 3 the reliability is adjusted to two different target levels, i.e., $R^{1}$ and $R^{3}$. The paths vary about the trend line because of the lumpy nature of the investments corresponding to each system expansion plan.

The present discounted values of the annual streams of future system supply costs (i.e., investment and maintenance) and outage costs (net of marginal generation costs of $\mathrm{KWH}$ not supplied because of outages) associated with expansion path $i$ are denoted by $S C_{t}^{i}$ and $O C_{t}^{i}$ and total costs $T C^{i}=O C^{i}+S C^{i}$. The expansion path $i$ which minimizes $T C^{i}$ also yields the optimum reliability level $R^{m}$. Since the system design process involves discrete jumps in $R$ rather than continuous variations, it is better to consider of a band of optimum reliability levels around $R^{m}$, rather than a unique value. Furthermore, the impact of the new reliability on price and demand should be examined iteratively, as discussed earlier. In this formulation the measure $R^{i}$ is an aggregate scalar quantity used for convenience to simply characterize a given system expansion path $i$. The process of choosing the optimum system design is carried out on the basis of an economic cost benefit analysis, and is quite independent of the actual measure of reliability.

The above cost-benefit simulation model is sufficiently general to optimize any part of a power system, i.e., at the generation, transmission, or distribution levels. However, in the illustrative case study presented next, only the distribution network is varied, whereas the reliab:lify of power delivered to the substation is exogenously fixed (i.e., generation and transmission reliability are held

\footnotetext{
${ }^{15}$ This measure is analogous to the loss of energy probability (L_OEP) critcrion used in generation system planning. For a review of the different reliability indices in cursent use, sec Munasinghe (forthcoming).
} 
FIGURE 1

CHARACTERIZATION OF ALTERNATIVE EXPANSION PATHS

ACCORDING TO THE RELIABILITY LEVEL

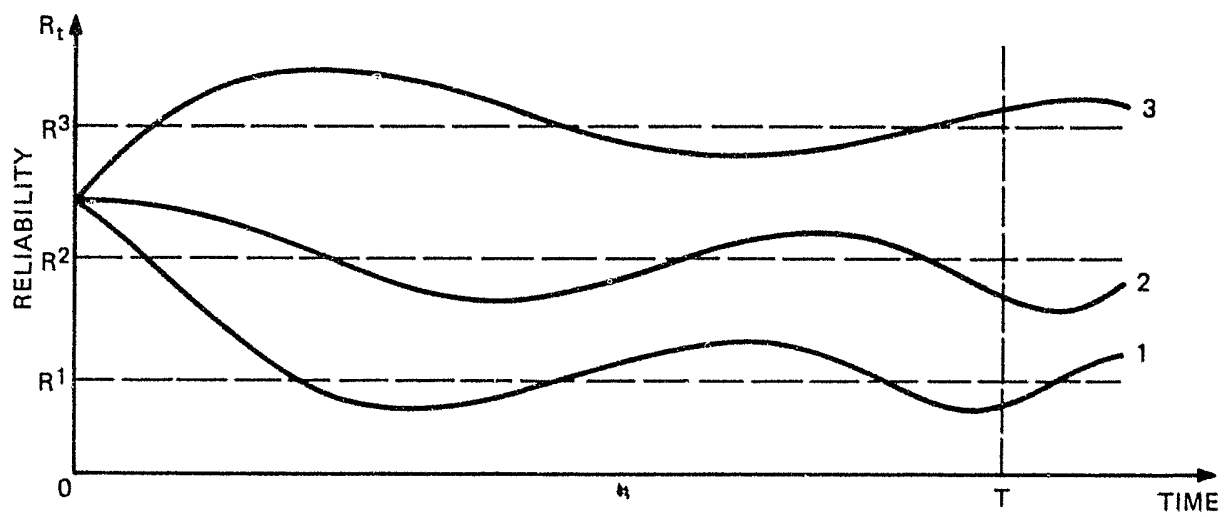

constant). A given improvement in reliability may, of course, be realized more economically by strengthening generation and transmission rather than distribution, but this is outside the scope of the case study.

\section{The case study}

The case study involves the optimization of the electric power distribution system servicing the Cascavel urban area, by comparing the costs and benefits of changes in the reliability level. The analysis is characterized by the high level of disaggregation required for distribution system planning. Twenty categories of consumers are identified: 4 residential income classes, 10 industrial sectors, 3 commercial categories (including government offices), public illumination, hospitals, and schools. The city is overlaid with a rectangular grid which divides up the urban area into 247 distinct cells $\left(0.5 \times 0.5 \mathrm{~km}^{2}\right)$, and the planning time horizon spans a 21-year period (1976-1996). The technical and engineering considerations by which the supply side costs were determined are briefiy summarized below. ${ }^{16}$

First, a demand forecast is made assuming a constant future real price level, disaggregated by consumer category, by geographic cell, and by year, over the plan period. For each consumer type, electricity consumption is correlated with one or more other explanatory variables which are relatively easy to predict. For residential consumers the relationship between KWH use and household income is combined with the projected growth of population and income, to forecast electricity consumption. In each industrial sector the future load is based on the value added per $\mathrm{KWH}$ and projected growth of value added. Similarly, the key relationships for commercial users, hospitals, and schools are KWH consumption per unit area of floor space, per hospital bed, and per student, respectively. These loads are allocated among the different geographic cells, for the plan period, starting with the existing pattern of consumers in 1976 available from the billing records of the local electric utility company, and using

\footnotetext{
${ }^{16}$ For details, see Munasinghe and Scott (1978).
} 
the Cascavel long-range urban development plan ${ }^{17}$ and zoning regulations to determine the future distribution of demand.

Next, several alternative distribution systems are designed to meet this load, each using a different target reliability criterion. Thus we distinguish four basic system designs to be called the low, medium $A$, medium $B$, and high reliability plans, respectively. Finally, the engineering analysis leads to a delermination of the total supply costs, and the expected annual frequency and duration of outages (by cell, over the plan period), corresponding to each basic system plan.

The chief global (or city-wide) sharacteristics of the basic alternative sy'stem plan are summarized in Table 2 . With respect to the four basic system designs. as the overall reliability level $(R)$ increases, outage costs $(O C)$ decline steadily, whereas supply costs $(S C)$ remain fairly stable until there is a sharp rise in $S C$ between the medium $B$ and high reliability plans. ${ }^{18}$ Outage costs per KWH lost $(O C K)$ tend to rise with increasing system reliability.

Table 3 indicates that both total energy use $(T E)$ and outage costs are most significant for residential and industrial consumers. For the range of reliability levels considered in this study, the main industrial group appears to be the one most affected by outages, in terms of $O C K$, followed by residential, service industrial, hospitals, and public illumination. $O C K$ for the main industrial category tends to increase as reliability increases (and the averige outage duration decreases), whereas $O C K$ does not vary much with sy'stem reliability for the other categories of users.

More detailed analysis (Munasinghe, forthcoming) indicates, that residential consumers suffer outage costs of about $\mathrm{Cr} \$ 16-22$ per $\mathrm{KWH}$ lost, over the range of reliability levels considered. This outage cost rises only slightly with income since those with higher incomes consume greater amounts of electricity. Industrial outage costs per KWH lost vary between Cr $\$ 37-76$ for the wood industry

TABLE 2

GLOBAL CHARACTERISTICS OF THE ALTERNATIVE DISTRIBUTION SYSTEM PLANS ${ }^{\prime}$

\begin{tabular}{|c|c|c|c|c|c|c|}
\hline SYSTEM PLAN & RELIABILITY: R & $\begin{array}{l}\text { OUTAGE RATE: } \\
\text { OR }(":)\end{array}$ & $\begin{array}{l}\text { OUTAGE COST: } \\
\text { OC }\left(10^{6} \mathrm{Cr} \$\right)^{-}\end{array}$ & $\begin{array}{l}\text { SUPPLY COST: } \\
\text { SC }\left(10^{6} \mathrm{CrS}\right)\end{array}$ & $\left|\begin{array}{c}\text { TOTAL COST: OC+SC } \\
\left(10^{6} \mathrm{CrS}\right)\end{array}\right|$ & $\begin{array}{l}\text { OUTAGE COST KIVH } \\
\text { LOST. OCKICIS. KWH) }\end{array}$ \\
\hline \multicolumn{7}{|l|}{ BASIC OESIGNS } \\
\hline 1 (LOW REL.) & 0.9935 & 0.650 & 150.1 & 57.5 & 207.6 & 14.0 \\
\hline $2 A$ (MED. REL.) & 0.9969 & 0.314 & 77.2 & 58.6 & 135.8 & $: 4.9$ \\
\hline 28 (MED. REL.) & 0.9981 & 0.191 & 49.5 & 57.8 & 107.3 & 15.7 \\
\hline 3 (HIGH REL) & 0.9988 & 0.116 & 28.4 & 76.9 & 105.3 & 14.8 \\
\hline \multicolumn{7}{|l|}{ HYBRIO DESIGNS } \\
\hline 4 (MED./HIGH REL.) & 0.9982 & 0.184 & 44.5 & 59.9 & 104.4 & 14.6 \\
\hline 5 (MED.'HIGH REL.) & 0.9983 & 0.166 & 44.3 & 65.2 & 109.5 & 16.1 \\
\hline 6 (MED. HIGH REL.) & 0.9984 & 0.159 & 39.3 & 67.4 & 106.7 & 14.9 \\
\hline \multicolumn{7}{|c|}{$\begin{array}{l}1 \text { PRESENT DISCOUNTED VALUES OF OUANTITIES, OVER THE PERIOD } 1976.2006 \text { AS OEFINED IN SECTION } 3 \text {; DISCOUNT } \\
\text { RATE }=12 \% \text {. }\end{array}$} \\
\hline \multicolumn{7}{|c|}{$2 O R=100 *(1-R)=100 * \frac{O E}{T E}$} \\
\hline
\end{tabular}

17 Plano Diretor do Desenvolvimento (1975).

${ }^{18}$ Plan $2 \mathrm{~B}$ is slightly cheaper although more reliable than Plan $2 \mathrm{~A}$, because of better devign aplimization. However, for this range of reliability $S C$ may be considered essentially constunt. 
TABLE 3

ENERGY USE AND OUTAGE COSTS BY MAJOR CONSUMER CATEGORY 1

\begin{tabular}{|c|c|c|c|c|c|c|c|c|c|}
\hline \multirow{2}{*}{$\begin{array}{l}\text { CONSUMER } \\
\text { CATEGORY }\end{array}$} & \multirow{2}{*}{$\begin{array}{c}\text { TOTAL FNFPGY: TE } \\
\text { (UNH) }\end{array}$} & \multicolumn{4}{|c|}{ OUTAGE COST: OC $\left(10^{6}\right.$ CrS) } & \multicolumn{4}{|c|}{ DUTAGE COST/KWH LOST: OCK (CrS/KWH) } \\
\hline & & PLAN 1 & PLAN 2A & PLAN 2B & PLAN 3 & PLAN 1 & PLAN 2A & PLAN 2B & PLAN 3 \\
\hline RESIDENTIAL & 48.4 .1 & 68.2 & 34.8 & 20.5 & 9.9 & 17.9 & 18.2 & 18.6 & 17.5 \\
\hline MAIN INDUSTRIAL & 371.8 & 77.4 & 40.5 & 27.8 & 17.8 & 31.4 & 33.5 & 30.0 & 26.5 \\
\hline SERVICE INDUSTRIAL & 224.7 & 4.1 & 1.6 & 1.0 & 0.6 & 3.4 & 3.2 & 3.8 & 3.6 \\
\hline PUBLIC LIGHTING & 60.4 & 0.2 & 0.1 & - & - & 0.4 & 0.4 & 0.4 & 0.4 \\
\hline HOSPITALS & 11.7 & 0.3 & 0.1 & - & - & 5.9 & 5.9 & 5.9 & 5.9 \\
\hline
\end{tabular}

down to $\mathrm{Cr} \$ 12-35$ for other industries. The outage costs results for industrial consumers are consistent with results from other studies, ${ }^{19}$ but our residential outage costs are much larger because in previous studies the value of foregone leisure was ignored..$^{20}$

As the results in Table 2 indicate, by progressing from Plan 1 to Plan 3, there is a steady improvement in overall reliability, a corresponding decrease in global outage costs $(O C)$, and a sharp increase in the distribution system supply costs $(S C)$ between Plans $2 \mathrm{~B}$ and 3 . Thus optimal distribution system design, where the total economic cost of distributing electricity in Cascavel $(O C+S C)$ is minimized, will likely occur somewhere in the region of Plans $2 \mathrm{~B}$ and $3 .^{21}$

Next, using the geographically disaggregate outage cost results, several hybrid distribution system designs are considered, based on the principle of high reliability service for high outage cost neighborhoods, and so on; the results are summarized in Table 2 . The results for hybrid plans 4,5 , and 6 indicate that Plan 4 , in which the main industrial zone is supplied at high reliability, while all other areas obtain medium $B$ reliability service, has the lowest total costs. Clearly, further fine tuning of the optimization procedure is possible by examining different parts of the city in greater detail and varying the design of the distribution system in these areas. However, for the purposes of this study, which is to demonstrate the application of the new methodology, we go no further than to identify an approximate range of reliability levels $0.13<O R$ $<0.16$ within which the optimum distribution system plan should lie.

\section{Conclusions}

The study demonstrates that it is possible to optimize the design of a longrange distribution system so as to minimize the total costs (i.e., sum of outage

${ }^{19}$ A range of values US $\$ 0-7$ per $\mathrm{KWH}$ lost have been reported for different industries by others. However, because of the wide variations in methouiology, different countries of application, and timing of these studies, the results are not strictly comparable. See Jamaica Public Service Co. (1975), Jaramillo and Skoknic (1973), Julius (1976), Kaufman (1975). Swedish Committee on Supply Interruption Costs (1968), Taiwan Power Company (1975), and Telson (1975).

${ }^{20}$ An exception is the Swedish Commitlee on Supply Interruption Costs (1968), which gave values of residential outage costs similar to ours; once again the results are not directly comparable.

21 Sensitivity analysis indicates that these results are relatively unaffected by a 10 percent change in the demand forecast, variations in the discount rates between 8 percent- 14 percent, or variations in shadow wage rate from 0.8 to 1.0 times the nominal wage rat: 
and system costs) to society. Since the economic methodology is quite general, it would be possible to treat generation and transmission system reliability in the same way; i.e., optimize the iesign of the whole electric power system. In addition, the method of measuring industrial outage costs can be used to identify those industries which are very sensitive to outages, and this information could be used to minimize the economic costs of load shedding.

The case study of Cascavel utilized data that were readily available, mainly from the local utility company, as inputs in the computer models used to determine the demand forecast, the alternative distribution system designs, and the resulting system and outage costs. Results indicate that the principal outage costs are incurred by industrial and residential consumers; and, this fact is reflected in the optimum design of the distribution system, with the high population density core city area and the industrial zone receiving the highest reliability service. Further fine tuning of the system is possible by varying the design in specific areas to obtain a better optimum.

If the optimum plan is adopted, which corresponds to the minimum $T C$ achievable after fine-tuning the procedure, it would result in a net saving of about Cr $\$ 8$ million (US\$0.65 million) in present value terms for Cascavel over the next 30 years, assuming that the alternative would have been Plan 3 in which the existing high level of reliability was maintained into the future over the whole city. Of this net saving, $\mathrm{Cr} \$ 15$ million would be the reduction in system costs, whereas outage costs would increase by $\mathrm{Cr} \$ 7$ million. If electricity revenues were reduced by $\mathrm{Cr} \$ 15$ million, we find that the consumers living in the medium reliability areas would pay on the average at least Cr $\$ 0.01$ less per $\mathrm{KWH}$ consumed ${ }^{22}$ than with Plan 3 . This change in the mean price caused by reliability level optimization alone is small compared, for example, to the average 1976 residential tariff of about Cr\$0.82 per KWH consumed.

Because every city has its specific characteristics, the results of the Cascavel case study cannot be used to draw wide-ranging conclusions regarding generally desirable, distribution system reliability levels for other cities in the developing countries. However, the methodology remains valid and could be applied elsewhere.

\section{Reỉerences}

Becker, G. "A Theory of the Allocation of Time." Frommil Journal (September 1965), pp. 493-517.

Crew, M.A. ANd Kleindorfer, P.R. "Peak Load Pricing with a Diverie Technology." The Bell Journal of Economics, Vol. 7, No. 1 (Spring 1976), pp. 207-231.

- AND - "Reliability and Public Utility Pricing." The American Economic Review", Vol. 68, No. 1 (March 1978), pp. 31-40.

Gronau, R. The Intrafamily Allocation of Time: The Value of Housewives 'Time. "The American Economic Review, Vol. 63, No. 4 (September 1973), pp. 634-650.

Jamaica Public Service Company. "Reliability Dollar Value Analy'sis" and "The Selection of a Generation Reliability Criterion for JPSC." November 1975.

Jaramillo, P. ANd Skoknic, E. "Costo Social de las Restricciones de Energia Electrica." Oficina de Planificacion, Chile, August 1973.

22 This assumes that the system cost saving of $\mathrm{Cr} \$ 15$ million is allocated to the $1,340 \mathrm{GWH}$ (in present discounted value terms) consumed by users outside the industrial zone. If the tariff of main industrial consumers within the industrial zone were raised to reflect their higher reliability' level, the average tariff for other areas of the city could be reduced further. Of course, if tariffs were based on marginal costs, the restructuring of prices would be different. 
Julıus, D. "The Economic Cost of Fower Outages: Meihodılogy and Application to Jamaica." EW\&T Department, World Bank, August 1976.

Kaufman, A. "Reliability Criterion-A Cost-Benefit Analysis." Office of Research, N.Y. State Public Service Commission, August 1975.

LANCASTER, K. "A New Theory of Consumer Behavior." Journal of Poltical Economy" (1966).

M. Munasinghe, "The Leisure Cost of Electric Power Failures." World Bank Staff Working Paper No. 285, World Bank, Washington, D.C., June 1978.

. The Economic's of Power System Reliability and Planning: Theory and Caso Study. Baltimore: Johns Hopkins, forthcoming.

AND Scotr, W, "Long-Range Distribution System Planning Based on Optimum Economic Reliability Levels." Paper No. A78576-1, Proceedings of the IEEE Power Lingineering Society Summer Meeting, Los Angeles, (August 1978).

Pricing of Electricity, State of the Art Conference on Marginal Cost Pricing, Montreal, April-May 1978.

Plano Diretor do Desenvolviniento. Prefeitura Municipal de Cascavel. Cascavel, Parana, Brazil, 1975.

Priestman, D. "The Cost of Long-Term Electrical Energy Shortage Due to Underplanning." Eleventh Annual Pacific . Northw'st Regional Economic Conference, Eugene, Oregon, May 1977.

Sherman, R. AND VisScher, M. "Second-Best Pricing with Stochastic Demand." The Ame'ri' 'un Economic Review, Vol. 63, No. 1 (March 1973), pp. 41-53.

SQuire, L. AND VAN DER TAK, H. Economic Analysis of Proje'c $/$. Baltimore: Johns Hopkins, 1975.

SWEDISH COMMITTEE ON SUPPLY INTERRUPTION COSTS. "Costs of Interruptions in Fleciricity" Supply." O.A. Trans. 450, The Electricity Council, UK, September 1968.

Taiwan Power Company. "Evaluation of Generating Capaclty Reserve." 1975.

TELSON, M.L. "The Economics of Alternative Levels of Reliability for Electricity' Generation System." The Bell Journal of Economics, Vol. 6, No. 7 (Autumn 1975), pp. 679-694.

TURVEY, R. AND ANDERSON, D. Fiectricity Economic's, Baltimore: Johns Hopkins, 1977, Chapter 2. WEBв, M. "The Determination of Keserve Generating Capacity Criteria in Electricity Supply." Applied Economics (March 1977), pp. 19-31. 
THE WORLD BANK

Headquarters:

1818 H Street, N.W.

Washington, D.C. 20433, U.S.A.

European Office:

66, avenue d'léna

75116 Paris, France

Tokyo Office:

Kokusai Building,

1-1 Marunouchi 3-chome

Chiyoda-ku, Tokyo 100, Japan

The full range of World Bank publications, both free and for sale, is described in the World Bank Catalog of Publicntions, and of the continuing research program of the World Bank, in World Bank Research Program: Abstracts of Current Studies. The most recent edition of each is available without charge from:

PUBLICATIONS UNIT

THE WORLD BANK

1818 H STREET, N.W.

WASHINGTON, D.C. 20433

U.S.A. 